\title{
Recent advances in boar semen cryopreservation
}

\author{
D. Rath', R. Bathgate' ${ }^{2}$ H. Rodriguez-Martinez ${ }^{3}$, J. Roca ${ }^{4}$, J. Strzezek ${ }^{5}$ \\ and D. Waberski ${ }^{6}$
}

'Institute of Farm Animal Genetics, Friedrich Loeffler Institute, Federal Institute of Animal Health, 31535 Neustadt-Mariensee, Cermany; ${ }^{2}$ Faculty of Veterinary Science, The University of Sydney, NSW 2006, Australia; 'Division of Reproduction, Faculty of Veterinary Medicine and Animal Sciences, SLU, SE-75007 Uppsala, Sweden; 'Department of Animal Medicine and Surgery, Faculty of Veterinary Medicine, University of Murcia, E-30071 Murcia, Spain; ${ }^{5}$ Department of Animal Biochemistry and Biotechnology, Faculty of Animal Bioengineering, University of Warmia and Mazury in Olsztyn, Poland; ${ }^{6}$ Unit for Reproductive Medicine of Clinics for Pigs and Small Ruminants, University of Veterinary Medicine Hannover, 30559 Hannover, Germany

\begin{abstract}
Since 35 years ago boar semen has been frozen and used for artificial insemination (AI). However, fertility of cryopreserved porcine sperm has consistently been low as boar sperm are more sensitive to cellular stress imposed by changing osmotic balance, oxidative stress, low-temperature exposure, cryo-protectant intoxication etc. and are less able to compensate for these deficiencies at commercially applicable dosages. Additionally, differences in sperm freezability among individuals are well known. Here we review current advances on tests to screen sperm quality post-thaw, on ways of diminishing individual boar effects, on improvement of cryoprotection by novel extender components, on packaging and freezing protocols and freezing and thawing methods, and on the handling of sexed boar sperm. Major advances have been registered, which have improved cryo-survival and the capacity to process boar semen for commercial Al.
\end{abstract}

\section{Introduction}

The history of boar sperm freezing is characterized by three major events. About 60 years ago Chris Polge found by chance that glycerol was an effective cryo-protecting agent (CPA); Pursel \& Johnson (1975) developed the Beltsville freezing and thawing procedure using a pellet method and Westendorf et al. (1975) started to freeze boar sperm in plastic straws. Since then important steps for freezing have been developed in laboratories around the world, but boar sperm cryosurvival has consistently been low. Throughout cryopreservation, sperm are exposed to cellular stress imposed by changing osmotic balance, oxidative stress, low-temperature exposure, and cryo-protectant intoxication. Apart from lethal changes due to cryo-injury, sub-lethal changes occur in sperm that take place at a molecular level, impacting on their cellular function and fertilizing capacity. Additionally, differences in sperm freezability among individuals are common. This review describes different perspectives and practical application of recent achievements in the improvement of the quality of frozen-thawed (FT-) boar semen. 


\section{Integrity of frozen thawed boar sperm}

Evaluation of frozen/thawed semen quality

Sperm kinematics assessed by computer-assisted sperm analysis (CASA) has great potential to give better insight into boar sperm function and heterogeneity. More than 30 different kinematic parameters related to linearity, velocity and lateral head displacement allow for detailed analysis of kinematic characteristics of single sperm. In addition to post thaw motility, the function of relevant sperm signal transduction systems, e.g. the activation of transduction systems (e.g. the activation of adenyl-cyclase) by short-term incubation with bicarbonate (Holt \& Harrison 2002; Satake et al. 2006) can be measured with CASA systems. Despite this potential, CASA parameters were not found to be very sensitive at monitoring cooling-associated changes of sperm function (Saravia et al. 2007) or predicting fertility of FT-sperm (Rodriguez-Martinez 2007). One reason for this is related to the inability of some CASA systems to examine populations and at the same time focus on individual sperm. Means and standard deviation of sperm kinematics are inappropriate to detect small populations of rapidly and linearly moving sperm, which may be significant for fertilization (Holt et al. 2007).

The main damage to sperm due to cryo-injury occurs at the level of the plasma membrane and appears to be more closely related to fertility than sperm motility (Rodriguez-Martinez 2007). Following detection by fluorescence techniques, about $50 \%$ of boar sperm are commonly classified as "dead" after freezing/thawing. The additional detection of sub-lethal changes in plasma membrane function impairing sperm fertilizing capacity seems to be of high diagnostic relevance. Membrane characteristics of thawed sperm are similar in certain respects with sperm that are in advanced stages of capacitation. Although they do not correspond completely at the molecular level, this phenomenon led to the idea of "cryo-capacitation" (Watson 1995; Green \& Watson 2001). Attempts to verify the occurrence of capacitating-like changes following cryopreservation were made by detecting phospholipid disorders in plasma membranes using the lipophilic fluophore Merocyanine-540 (Harrison et al. 1996) and by induction of acrosome exocytosis using calcium ionophore A23187 in presence of bicarbonate as capacitation inducer (Guthrie \& Welch 2005a). Compared to fresh semen, cryo-preserved sperm showed a reduced response to bicarbonate (Guthrie \& Welch 2005a; Saravia et al. 2007). The presence of lipids and proteins of seminal plasma (SP) and/or egg yolk may alter the response to bicarbonate rather than the cooling process itself (Guthrie \& Welch 2005b; Saravia et al. 2009b). Additionally, the sequential manner in which capacitational changes occur and contribute to a destabilization process leading to cell death (Petrunkina et al. 2007) may differ between fresh and FT- sperm. FITC-conjugated Annexin- $V$ has been used to measure phospholipid scrambling by specifically binding to phosphatidylserine molecules that accumulate in the plasma membrane exoplasmic leaflet (Gadella \& Harrison 2002). Cryo-preservation caused a significant increase in AnnexinV-positive staining in live sperm (Peña et al. 2003; Guthrie \& Welch 2005b). It is suggested that increased Annexin-V-binding in thawed sperm results from plasma membrane damage incurred during freezing and thawing (Guthrie \& Welch 2005b), rather than from expression of capacitation (Silva \& Gadella 2006; Rodriguez-Martinez 2007).

Detection of early changes in the sperm plasma membrane at any of the main three domains is very important for cryo-storage protocols. During cryo-preservation the major osmotic gradient across the sperm membranes essentially changes with sperm undergoing volumetric changes as water and solute leave and enter the cells. This osmotic response can be potentially lethal to the sperm if it causes them to swell or shrink beyond their osmotic tolerance limits. Cell death occurs mainly during the thawing process, when the dehydrated sperm are exposed to severely hypo-osmotic conditions (Gilmore et al. 1996). Electronic volume measurements by 
cell counter display the response of large numbers of sperm to osmotic challenges including the identification of subpopulations with different osmotic responsiveness. A relationship of volumetric parameters to fertility was established for frozen bull sperm (Petrunkina et al. 2001) and sperm binding to oviductal explants in vitro seems to be related to fertility of frozen semen (De Pauw et al. 2002; Khalil et al. 2006). However, a prediction of fertility remains questionable due to difficulties in standardizing the assay and loss of tissue differentiation during culture. Microscopic assessment of cryo-preserved boar sperm using a simplified hypo-osmotic swelling test gave comparable results to flow cytometrically analyzed plasma membrane integrity, despite measuring different membrane domains (Saravia et al. 2005) and is significantly related to fertility (Perez-Llano et al. 2001).

Oxidative stress during the freezing-thawing cycle due to excessive generation of reactive oxygen species (ROS) or deficiencies in the antioxidant defense system can induce serious damage to many biological macromolecules, such as proteins, lipids and mitochondrial DNA ( $m$ tDNA) as well as nuclear DNA (nDNA), which could lead to impaired biological properties and eventually to cell death (Aitken \& Baker 2004). Pro-apoptotic changes in cryo-preserved sperm are characterized by increased $\mathrm{Ca}^{2+}$ concentration, disturbance in mitochondrial membrane potential, reduced ATP levels and the release of pro-apoptotic factors in the cytoplasm (Martin et al. 2004, 2005; Peña et al. 2009). Different methods used to assess nuclear DNA damage after freezing and thawing have so far given controversial results. DNA fragmentation as detected with single cell gel electrophoresis (comet assay) was significantly increased in FT- compared to fresh sperm and was affected by the individual boar (Fraser \& Strzezek 2005), the presence and type of the cryo-protectant, and by seminal plasma (SP) (Fraser \& Strzezek 2007b; Hu et al. 2008). In contrast, although the sperm chromatin structure assay (SCSA) did not reveal biologically significant changes due to sperm freezing/thawing in unselected boars (Saravia et al. 2009b), sires classified as "good freezers" were less susceptible to sperm chromatin denaturation than "bad freezers" (Hernández et al. 2006). Varying results among different studies may depend on the innate variation among boars used but, since most stud boars have been selected for sperm quality, such differences are minor and only appear in a small number of males $(<1 / 1,000)$ it is more likely that the tests need further standardization. DNA fragmentation assays as determined by single cell electrophoresis may be less accurate as it is based on single cell determination and cannot distinguish between dead and live sperm.

\section{Boar-to-boar variation on sperm freezability}

As for many other mammals (Holt et al. 2005, Loomis \& Graham 2008), male-to-male variability in post-thaw sperm quality has been extensively demonstrated in pigs (Larsson \& Einarsson 1976, Thurston et al. 2001, Medrano et al. 2002a, Saravia et al. 2005, Roca et al. 2006b). This individual variability is the primary factor explaining differences in sperm cryo-survival between boars (Roca et al. 2006a). However, since ejaculates within a given male most often respond reproducibly to the same cryo-preservation protocol, grouping of sires as "good", "moderate" or "poor" sperm freezers can be done, based on post-thaw sperm quality. Between 20 to $33 \%$ of stud sires are considered "poor" sperm freezers (Thurston et al. 2002, Roca et al. 2006a, 2006b, Hernández et al. 2007a), most likely genetically driven. Thurston et al. (2002) compared the genomic DNA of boars using the Amplified Fragment Length Polymorphism (AFLP) technique and identified different AFLP profiles between "good" and "poor" sperm freezers. Some of these profiles were related to post-thaw sperm quality and were, therefore, considered to represent significant markers of sperm cryo-sensitivity. The underlying mechanism(s) for the genetic differences related to cryo-preservation-induced sperm injuries are yet unknown but may represent differences in 
sperm biochemical composition and physiology (Holt et al. 2005). Whether the polymorphism of testis- and epididymisexpressed candidate genes affecting sperm quality traits in fresh boar semen (Lin et al. 2006) are linked to cryo-preservability remains to be proven. In this context, Waterhouse et al. (2006) showed a relationship between long-chain polyunsaturated fatty acids in the plasma membrane of thawed sperm and boar-to-boar differences in sperm cryo-sensitivity. These inter-boar differences might equally be, however, related to variations in SP composition. Rath \& Niemann (1997) observed that boar differences in post-thaw motility were only significant for ejaculated sperm, whereas epididymal sperm had a consistently higher post-thaw motility. More recently, Saravia et al. (2007) showed a significant improvement of sperm cryo-survival together with a substantial reduction of boar-to-boar variability on post-thaw sperm quality when cryo-preserving just the first $10 \mathrm{ml}$ of the sperm-rich fraction of the ejaculate, a portion characterized by the highest sperm concentration alongside with low presence of sex gland secretions. Altogether, these results seem to indicate that the exposure of sperm to the SP during the ejaculation process could modify their cryo-sensitivity.

Minimization of the negative effects of boar-to-boar variability on post-thaw sperm quality within the commercial semen freezing industry should first be addressed towards identification of potentially "good" or "poor" sperm freezers. In absence of a simple blood-based genetic test and given the fact that sperm freezability is highly consistent within stud boars (Roca et al. 2006a), the potential sperm freezability of a given boar can be identified by means of sperm freezability tests (SFT), consisting of the cryo-preservation of $5-10 \mathrm{ml}$ of just one ejaculate per boar. Experience from Spain over the past 12 years indicates that implementing a SFT can predict its relative sperm freezability potential. After performing the SFT-test, 112 boars $(24.6 \%)$ showed $\leq 35 \%$ viable and motile sperm after thawing and were considered as "poor" sperm freezers. Additionally, action should be taken towards the improvement of sperm cryo-survival of ejaculates collected from boars classified as "poor" sperm freezers. The ability to cryo-preserve ejaculates from "poor" sperm freezers remains important in the context of genetic resource banking and international exchange of genetic material (Holt et al. 2005). Such action could be undertaken by customizing the cryopreservation protocol. An example is by individually-tailoring the freezing-thawing protocol, a concept suggested by Watson (1995) and recently applied by Hernández et al. (2007b) using a so called "split-ejaculate freezing test". Individual ejaculates were divided and cryo-preserved using 12 different protocols that differed with regard to cooling rate, glycerol concentration or warming rate. Significant interaction was found between ejaculate and cryo-preservation protocol, with the influence of glycerol concentration and warming rate being particularly relevant for post-thaw sperm quality. Such handling reduced the percentage of "poor" freezers from 26.4 to $7.5 \%$. An alternative has been recently presented by cryo-preserving the first $10 \mathrm{ml}$ of the sperm-rich fraction of each ejaculate (Rodriguez-Martinez et al. 2008; Saravia et al. 2009a, b).

\section{Cryo-injury in boar sperm}

The sperm membrane is regionally differentiated and displays different behaviour and interactions depending on structural regions. The acrosome (especially the equatorial segment), the post-acrosomal and mid-piece segment and, the principal and end tail segments, are all structurally and functionally crucial to sperm function. Cryo/thawing-protocols cause loss of selective permeability and integrity of these domains, mostly during rewarming (Medrano et al. $2002 \mathrm{~b}$ ). Inadequate ice formation and the subsequent osmotic stress induced during freezing and re-warming are the two major factors responsible for sperm cryo-injury (Watson 2000) and compromise sperm function due to alterations in the membrane constituents, particularly lipids and proteins. These phenomena might be associated with pro-apoptotic changes in sperm caused by reactive oxygen species (ROS) produced under stress conditions. 
Protein tyrosine phosphorylation, which plays a crucial role in the regulation of cell proliferation and differentiation, is associated with capacitation-like changes in sperm, sometimes termed "cryo-capacitation" when induced by cryo-preservation (Urner \& Sakkas 2003, Bravo et al. 2005). The level of phosphorylation of tyrosyl groups is regulated by the balance of protein tyrosine kinases (PTKS) and protein tyrosine phosphatases (PTPases). Phosphorylation of tyrosine residues in sperm varies among boars and at different stages of the cryo-preservation procedure according to the "Kortowska" method (Strzezek et al. 1985). Recently it has been demonstrated that fresh semen from boars with good freezability was characterized by a low content of phosphotyrosine residues in the extracted sperm proteins, whereas semen from boars with poor freezability exhibited a high content of phosphotyrosine (Wysocki et al. 2009). Accordingly, phosphotyrosine proteins in sperm extracts could be dephosphorylated by the molecular form of acid phosphatase of boar SP (Wysocki \& Strzezek 2003, 2006) and phosphotyrosine residues in sperm proteins could be completely dephosphorylated only by acid phosphatases isolated from the vesicular glands.

\section{New approaches to improve the cryo-survival of boar sperm}

\section{Cryo-protectant agents}

The biophysical changes brought about by the transition of water to ice during the relatively slow cooling most often used are the assumed main causes for sperm damage. If sperm are solely frozen in SP (neat semen) or extended with a buffer, such "unprotected freezing" is simply lethal, since ice is formed both extra- and intra-cellularly, damaging essential cell structures, particularly the membranes of organelles and the plasma membrane. Even when the extender contains a proper cryo-protectant agent (CPA), damage occurs, but many cells survive the process. Under these conditions, ice is formed in the aqueous extender medium surrounding the sperm and, as ice crystals grow in this extracellular milieu of free water, the amount of solvent decreases while the solute becomes more and more concentrated. Sperm lose intracellular water in order to compensate for this effective osmotic stress leading to a freeze-dehydration of the cells. Eventually, when temperatures pass $\sim-80^{\circ} \mathrm{C}$, the highly concentrated, viscous solution within and outside the sperm turns into a relatively stable glassy matrix, which is basically maintained when sperm are stored at $-196^{\circ} \mathrm{C}\left(\mathrm{LN}_{2}\right)$. The imaging of such concentrated medium, where sperm are embedded (the so-called veins) contrasts with the frozen free water (so-called lakes), when viewed using a cryo-scanning electron microscope (Cryo-SEM, Ekwall 2009). Interestingly, most sperm in the veins appear intact, i.e. they seem to survive the process of cooling. Even more interesting, intracellular ice is rarely formed, since the speed of cooling is usually low and the presence of the CPA increases viscosity, both of which add to the above process of cell dehydration (Bwanga et al. 1991a). Most cells are damaged during thawing, with membranes and axonemes deteriorating by the osmotic imbalance that has been created during cooling (Morris 2006; Morris et al. 2007).

As mentioned above, glycerol was the first recorded CPA added to a semen extender. This small, poly-hydroxylated solute is highly soluble in water interacting by hydrogen bonding and permeates across the plasma membrane at a low rate. Glycerol is, unfortunately, cell-toxic at body temperature and thus boar sperm are usually exposed to glycerol at $\sim 5^{\circ} \mathrm{C}$, which further slows permeation. Mixed with the other solutes of the extender in solution, it depresses the freezing point and ameliorates the rise in sodium chloride concentration during dehydration. Moreover, glycerol increases viscosity with lowering temperature to more than $100,000 \mathrm{cP}$ at $-55^{\circ} \mathrm{C}$ (Morris et al. 2006) retarding both ice crystal growth and dehydration speed on a kinetic basis. Glycerol also eliminates eutectic phase changes of the extender (Han \& Bischof 2004), 
thus becoming a very suitable CPA when added at 2-3\%. It does not affect sperm cryo-survival in boars considered good freezers, and improves cryosurvival in those considered "moderate or bad freezers" (Hernández et al. 2007a).

A broad range of other solutes (mostly alcohols, sugars, diols and amides) has also been tested for CPA capacity (Fuller 2004). CPA capacity differed greatly in tests using boar sperm compared to the sperm of other species. Alcohols and diols can induce the formation of blebs, which are spherical cellular protrusions in the membrane. Sugars, which both increase viscosity and stabilize the membrane by interacting with phospholipids, have not led to a higher cryosurvival compared to glycerol (Hu et al. 2008). Replacing glycerol with amides (formamide; methyl-or dimethylformamide, MF- DMF; acetamide; methyl-or dimethylacetamide (MA-DMA) at $\sim 5 \%$ concentration, has proven acceptable (Bianchi et al. 2008). Although cryo-survival was not dramatically enhanced in most boars, cryo-susceptible boars benefited somewhat from use of DMA, probably because the amide permeates the plasma membrane more effectively than glycerol, thus causing less osmotic damage during thawing. Additives other than CPAs increase cryo-survival too. At very low rates $(<0.1 \%) \mathrm{N}$-acetyl-D-glucosamine has been able to enhance cryo-survival of boar sperm ( $\mathrm{Yi}$ et al. 2002a) possibly interacting with the surfactant Orvus es Paste (OEP) (Yi et al. 2002b). The value of OEP or other surfactants has been confirmed (Karosas \& Rodriguez-Martinez 1993, Pettitt \& Buhr 1998) when used with egg yolk (Buranaamnuay et al. 2009). Use of low-density lipoproteins (LDL), most often isolated from egg-yolk from different species (Fraser \& Strzezek 2007a; Jiang et al. 2007) has proven beneficial for sperm function post-thaw, particularly for DNA-integrity (see below).

\section{Lipoproteins}

Typically, boar sperm cryo-storage media contain up to $20 \%$ chicken yolk, whose active component (i.e. the low-density lipoprotein (LDL)-fraction), has been suggested to be largely responsible for protecting sperm against cold shock damage (Demianowicz \& Strzezek 1996; Moussa et al. 2002; Jiang et al. 2007, Hu et al. 2008). Despite some success in species such as the horse (Clulow et al. 2007), yolks from duck and quail failed to improve the post-thaw quality of frozen boar sperm (Bathgate et al. 2006). In contrast lyophilized lipoprotein fractions isolated from ostrich egg yolk (LPFo) provided good protection of sperm cells by preventing physical damage and alteration of membrane fluidity during cooling at variable temperatures (i.e. from $50 \mathrm{C}$ to $16^{\circ} \mathrm{C}$ or from $16^{\circ} \mathrm{C}$ to $5^{\circ} \mathrm{C}$ ) and cryo-preservation (Strzezek et al. 2004; Strzezek et al. 2005a). Besides its protective action, LPFo has been shown to possess specific antioxidant properties (Strzezek et al. 2004). The overwhelming positive effects of LPFo on sperm quality characteristics have led to the development of a new semen preservation technology for liquid storage at different temperatures and cryo-preservation (Fraser \& Strzezek 2005; Fraser \& Strzezek 2007a,b). Moreover, Al of sows with liquid-stored or FT-semen supplemented with LPFo gave acceptable results (Fraser et al. 2007a). Investigations on the interaction between yolk lipoproteins and SP-proteins indicated that together they either enhance (Manjunath et al. 2002) or diminish (Vishwanath et al. 1992) sperm cryo-protection, suggesting that revisiting storage media without egg yolk could provide a more biosecure means of transporting and storing boar sperm by avoiding (contaminated) materials from other species.

\section{Seminal plasma}

The SP has a chequered history as a supplement for sperm storage media and current opinion is still divided over its benefits. The binding of SP-proteins to sperm stabilizes the plasma membrane components, masks the antigens exposed to the cell surface and prevents premature acrosomal 
reaction (Muiño-Blanco et al. 2008). The boar SP contains a wide range of components that differ between species, males and ejaculates (Maxwell et al. 2007). This may explain the disparate results reported by different groups. It is now clear that mammalian SP contains components that can both inhibit and induce sperm capacitation, stimulate sperm motility and even provide protection against damage incurred during manipulation and storage, such as extension and coldshock (Maxwell et al. 2007). The major proteins identified to date in boar SP are the non-heparinbinding proteins PSPI/PSPII heterodimer (PSPI/PSPII), the heparin binding spermadhesins AQN-1, $A Q N-3, A W N$ and the lipid-binding protein $\mathrm{pB} 1$. PSPI/PSPII, more specifically the PSPII subunit, inhibits zona penetration and increases sperm longevity, suggesting that this subunit can be used to improve the fertility achieved with stored sperm (Caballero et al. 2008). Incubation of FT-sperm with PSPI/PSPII prior to in vitro insemination resulted in an increased proportion of viable sperm but a reduced number of penetrated oocytes, compared with sperm incubated without PSPI/PSPII. The same treatment applied to fresh sperm had no effect on oocyte penetration (Caballero et al. 2004). Fertility was also improved after laparoscopic insemination of low doses of sex-sorted sperm pre-incubated in the presence of PSPI/PSPII (Garcia et al. 2007). The PSPI/PSPII heterodimer has also been shown to modulate the uterine immune response to the introduction of semen in both an inhibitory (Veselský et al. 1992) as well as a stimulatory manner (Rodriguez-Martinez et al. 2005), suggesting a direct effect on spermatozoa as well as a preparatory role for embryo attachment. Thus, addition of PSPI/PSPII to the sperm suspension medium prior to insemination may be influencing fertility by the modulation of both sperm function and the secretory and/or physical environment of the female reproductive tract.

$A Q N-1$, a major heparin-binding protein prevalent in boar SP, may have a role in the congregation of sperm in the isthmic reservoir (Ekhlasi-Hundrieser et al. 2005) and both AQN-1 and -3 may regulate the initiation of capacitation (Dostalova et al. 1994). AWN appears to modulate sperm-oocyte interaction (Rodriguez-Martinez et al. 1998), suggesting that addition of these proteins to sperm prior to artificial insemination may improve fertility outcome. The lipid-binding protein pB1 has been implicated in the capacitation of epididymal boar sperm (Plucienniczak et al. 1999; Lusignan et al. 2007). Unlike homologous proteins found in the SP of other species, $\mathrm{pB} 1$ forms a complex with AQN-1 (Calvete et al. 1997). Manipulation of boar sperm storage media to remove this complex might prolong the shelf-life of sperm, or it could be exploited as a capacitation factor prior to IVF.

SP-vesicles (prostasomes) have been regarded as influencing fertility in humans (Kravets et al. 2000). Although probably of prostate origin, such has not yet been identified in the boar. Prostasomes consist of lipid and protein conglomerates that are concentrated in the sperm-rich fraction of the boar ejaculate but are of unknown function in this species (El-Haji Ghaoui et al. 2007). Similar structures in other species have been identified as fusing with sperm membranes, possibly stabilizing the lipids and postponing the acrosome reaction (Frenette et al. 2002).

Recently, it has been shown that a 5-h period of dialysis of boar ejaculate in semi-permeable dialysis bags ( 12 to $14 \mathrm{kDa}$ cut-off) prior to freezing had a significant effect on the polypeptide profiles of the SP (Strzezek et al. 2005b) as well as a significant improvement in post-thaw sperm quality characteristics, such as caffeine-stimulated sperm motility, plasma membrane integrity and mitochondrial status (Fraser et al. 2007b). Dialysis of ejaculates prior to freezing may be a useful technique to eliminate certain seminal plasma proteins with sperm toxic effects during cryo-preservation (Strzezek et al. 2005b).

\section{Other additives}

Boar sperm are susceptible to peroxidative damage induced by the cryo-preservation process (Hernández et al. $2007 \mathrm{c}$ ) due to the high proportion of unsaturated fatty acids present in their 
membranes (Cerolini et al. 2000). Hence, attempts have been made to add various antioxidants to different fractions of boar ejaculate to improve post-thaw sperm survival (Peña et al. 2003, Gadea et al. 2005), including butylated hydroxytoluene (BHT; Roca et al. 2004), catalase, superoxide dismutase (SOD; Roca et al. 2005), reduced glutathione (GSH; Woelders et al. 1996), and $\alpha$-tocopherol (Breininger et al. 2005). The latter reduced cryo-induced oxidative damage to sperm membranes, protein tyrosine phosphorylation and the capacitation-like events (Satorre et al. 2007).

Additional additives that have shown some potential for improving quality of boar sperm post thaw are hyaluronan (Peña et al. 2004), platelet-activating factor (PAF; Kordan \& Strzeżek 2002; Bathgate et al. 2007a) and platelet-activating factor: acetylhydrolase (Pafase; Bathgate et al. 2007a). PAF, a member of the family of the acetylated glycerophospholipids, is a component of plasmalemma lipids of boar sperm. PAF is involved in several sperm functions, including capacitation, the acrosome reaction and the regulation of motility of sperm, particularly during storage at $5^{\circ}$ to $16^{\circ} \mathrm{C}$ (Kordan \& Strzezek 2002). Supplementation of the cryo-preservation medium with PAF or the recombinant PAF acetylhydrolase appeared to have beneficial effects on the in-vitro quality of FT-sperm (Bathgate et al. 2007a).

\section{Controlled freezing}

Rates of cooling (and of thawing) can be controlled by use of programmed freezers, and "optimal" cooling rates are those that substantially diminished the period during which heat was released in the sample when water changed phases (i.e. ice was formed). Interestingly, experimentally determined optimal rates of the range $30-50^{\circ} \mathrm{C} / \mathrm{min}$ (Thurston et al. 2003) have been theoretically predicted (Devireddy et al. 2004; Woelders \& Chaveiro 2004) and confirmed by use of novel procedures, such as equilibrium freezing (Woelders et al. 2005). Boar sperm are still "best" (in terms of cryo-survival) cryo-preserved in standard lactose-egg yolk (or LDL)-based cooling and freezing media, the latter including a surfactant (often OEP) and glycerol $\left(2-3 \%\right.$ final concentration); cooled at 30 to $50^{\circ} \mathrm{C} / \mathrm{min}$ and rapidly $(1,000-1,800$ ${ }^{\circ} \mathrm{C} / \mathrm{min}$ ) thawed. This protocol would serve most boars while for those with sub-optimal sperm freezability, the protocol must be modified, particularly regarding glycerol concentration and warming rates (Hernández et al. 2007b). The entire procedure takes most often 8-9 hours from collection to storage of the frozen doses in $\mathrm{LN}_{2}$, is still tedious and inconvenient, and produces few Al-doses.

\section{Packaging systems}

The use of different packaging for extended sperm resulted in differences in cryo-survival. Boar sperm were processed in plastic straws of different volumes $(0.25$ to $5 \mathrm{ml})$ (Johnson et al. 2000), in flattened $5 \mathrm{ml}$ straws (Weitze et al. 1987), in aluminium tubes (Fraser \& Strzezek 2007b) or plastic bags of various types and constitution (Bwanga et al. 1991b; Karosas \& RodriguezMartinez 1993; Mwanza \& Rodriguez-Martinez 1993; Ortman \& Rodriguez-Martinez 1994; Eriksson \& Rodriguez-Martinez 2000a, b). The latter, denominated "FlatPack sw", proved equally good or better than $0.25 \mathrm{ml}$ straws in terms of sperm cryo-survival, despite the fact that they held $5 \mathrm{ml}$ of semen, which could accommodate an entire dose for cervical Al with 5 billion sperm, thus pooling innumerable straws after thawing was not necessary. The use of FlatPack ${ }^{\mathrm{mm}}$ resulted in acceptable farrowing rates and litter sizes (Eriksson et al. 2002). FlatPack ${ }^{\text {im }}$ was considered as cryo-biologically convenient to dissipate heat during rapid cooling and warming as those smaller containers tested. 
However, doses with such large sperm numbers are not the best use of the ejaculates. Since the introduction of intrauterine deposition of semen, small numbers of sperm are sufficient for successful insemination and the reduced volume of the dosage allowed the use of smaller containers. Recently, boar sperm have been frozen in highly concentrated (1-2 billion sperm/ $\mathrm{ml}$ ) small volumes (0.5-0.7 ml) in novel containers, the so-called "MiniFlatPack "iw" (Saravia et al. 2005). Interestingly, cryo-survival in MiniFlatPacks was equal or higher than survival in $0.5 \mathrm{ml}$ plastic straws, suggesting the shape maintained the cryo-biological advantages of the FlatPack ${ }^{\mathrm{m}}$ (Ekwall et al. 2007), including improvements in fertility (Wongtawan et al. 2006).

\section{New simplified freezing of boar semen}

Processing semen in the current manner is impractical and, therefore, unattractive for routine, commercial use. Sperm from boars that were semino-vesiculectomised sustained freezing and thawing equally well compared to sperm exposed to seminal vesicular proteins (Moore \& Hibbitt 1977), indicating that the SP of the sperm-rich fraction (SRF) might not be necessary for cryo-survival or even fertility. Recently, it was determined that boar sperm contained in the first $10 \mathrm{ml}$ of the SRF (also called Portion 1 or P1, containing about $1 / 4$ of all sperm in the SRF) were more resilient to handling (from extension to cooling) and cryo-preservation than the sperm contained in the rest of the ejaculate (Peña et al. 2003; Saravia et al. 2007; RodriguezMartinez et al. 2008). It appeared that it was actually the SP in this Portion 1 that was beneficial for sperm, either because of its higher contents of cauda epididymal fluid, its lower amounts of SP-spermadhesins or its lower bicarbonate levels. An attempt was very recently made to simplify the cryo-preservation protocol by freezing solely the P1-sperm, in concentrated form for eventual use with intrauterine Al. These sperm were packed into MiniFlatPacks ${ }^{\text {TM }}$ for customary freezing using $50^{\circ} \mathrm{C} / \mathrm{min}$ cooling rate. This "simplified" entire procedure, lasted 3.5 h compared to the "conventional freezing", which lasted $8 \mathrm{~h}$. As controls, sperm from the SRF were compared to P1-sperm. Cryo-survival was equally good (above $60 \%$ of the processed cells, Saravia et al. 2009a).

There are several advantages to using this simplified, shorter protocol, namely the exclusion of primary extension and of recovering this conspicuously beneficial SP-aliquot by centrifugation; as well as waiving the need of an expensive refrigerated centrifuge. Moreover, inter-boar variation was minimized by use of P1-sperm, which, not only were the "best" sperm to be cryo-preserved, but also left the rest of the collected sperm for liquid semen processing. This simpler protocol ought to be an interesting alternative for Al-studs to freeze boar semen along with production of conventional semen doses for $\mathrm{Al}$ with liquid semen.

\section{Advanced insemination strategies with FT- boar semen}

Recently, farrowing rates ranging from 72 to $85 \%$ and 11-12 piglets born per litter have been achieved in FT-inseminated sows in Taiwan and Canada with semen cryo-preserved in Europe (Eriksson et al. 2002; Roca et al. unpublished observations). These results indicate that FT-semen has the potential for sufficient fertilization rates and can be used to improve international semen trade. However, the high sperm number currently required per Al-dose (5-6 $\left.\times 10^{9} \mathrm{sperm}\right)$ together with the sometimes inconsistent fertility, limit FT-semen usage to the introduction of genetics.

Therefore, it is of utmost importance to reduce the number of sperm per Al-dose without impairing fertility. At present, this objective can be achieved by means of the deep intrauterine insemination (DUI) procedure, which allows deposition of the sperm dose deep into a 
uterine horn. Recently, the performance of DUI for swine Al and its suitability for an efficient application of FT-semen have been extensively evaluated (Bathgate et al. 2005; Roca et al. 2006c; Grossfeld et al. 2008; Vazquez et al. 2008). Overall, DUI appeared as a safe procedure leading to satisfactory fertility with as few as $1-2 \times 10^{9} \mathrm{FT}$-sperm per Al-dose. In this manner, in two more representative studies, farrowing rates above $70 \%$ with more than 9 piglets born per litter were achieved after insemination of 500 weaned sows under commercial conditions (Roca et al. 2003; Bolarin et al. 2005). Transcervical insemination could be another suitable Al-procedure for FT-semen, to allow deposition of sperm into the uterine body (Roca et al. 2006c). Unfortunately, it has been scarcely used with FT-semen, despite the promising fertility results achieved with liquid semen (Watson \& Behan 2002; García et al. 2007). In the only report found using FT-semen, Abad et al. (2007) reported farrowing rates below $50 \%$ in weaned sows inseminated with $3 \times 10^{9}$ live FT-sperm.

Fertility using commercial AI of FT-semen varies among trials, depending more on the interval between $\mathrm{Al}$ and ovulation than either post-thaw sperm quality or the sperm number inseminated. FT-sperm have a very short functional life span in the female genital tract, such that their fertilizing ability is dramatically impaired when inseminations are performed outside an interval 4-8 h before expected ovulation time (Wongtawan et al. 2006). Bolarin et al. (2005) achieved high farrowing rates above $80 \%$ in weaned sows using DUI with either $1-2$ $\times 10^{9}$ sperm per Al-dose, provided that the $4-8 \mathrm{~h}$ interval from $\mathrm{Al}$ to ovulation was respected. However, in contrast to these excellent results, the same authors and others (Wongtawan et al. 2006) achieved very low farrowing rates in sows using DUI outside of this "safe" pre-ovulatory interval, independent of how many living sperm were inseminated. Therefore, it is imperative that an accurate prediction of ovulation time is made to define an appropriate insemination timetable when FT-semen is used. As spontaneous ovulation takes place when two-thirds of the standing oestrus period has elapsed (Soede \& Kemp 1997), appropriate insemination timetables can be established when the duration of standing oestrus is known. Finally, because seasonal differences in farrowing rates are greater for FT-semen than for liquid semen (Bolarin et al. 2008), the influence of season on the elapsed time between onset of oestrus and ovulation should also be considered.

\section{Special freezing protocols for sex sorted boar sperm}

A special application for FT-semen is related to sex sorted sperm. Currently, freshly collected boar sperm have been sexed successfully by flow cytometry and offspring were produced by surgical insemination (Johnson 1991), IVF (Rath et al. 1997, 1999; Abeydeera et al. 1998), ICSI (Probst \& Rath 2003), and DUI (Rath et al. 2003; Grossfeld et al. 2005) under laboratory conditions. Due to the limited throughput of the sorting technology, a broader commercial application is not possible. Cryo-preservation might be a method of storage between sorting and insemination. Only a few studies investigated the freezing and thawing of sexed boar sperm. Sexed, frozen/ thawed sperm have been subjected to IVF and DUI (Bathgate et al. 2007b, 2008). Whereas invitro fertilization with FT sperm was successful and pregnancies were initiated (Bathgate et al. $2007 \mathrm{~b}$ ), all sows returned to oestrus within 57 days. A combination of low sperm numbers and potentially compromised developmental capability of embryos derived from sex-sorted sperm may have resulted in this early stage loss of pregnancy based on fertilization with spermatozoa that are affected by non compensable defects (Bathgate et al. 2008). 


\section{Acknowledgements}

Authors' own studies have been funded by the Development Association for Biotechnology Research (FBF), Bonn, Germany; the Australian Pork Limited (APL); FORMAS and the Swedish Farmers' Foundation for Agricultural Research (SLF), Stockholm, Sweden; CICYT (AGL2005-00760), Madrid and GREM (04543/07) Murcia, Spain and the National Centre for Research and Development, Warsaw, Poland (NR12001404).

\section{References}

Abad M, Garcia JC, Sprecher DJ, Cassar C, Friendship RM, Buhr MM \& Kirkwood RN 2007 Effect of insemination-ovulation interval and addition of seminal plasma on sow fertility to insemination of cryopreserved sperm. Reproduction in Domestic Animals 42 418-422.

Abeydeera LR, Johnson LA, Welch GR, Wang WH, Boquest AC, Cantley TC, Rieke A, Day BN 1998 Birth of piglets preselected for gender following in vitro fertilization of in vitro matured pig oocytes by $X$ and $Y$ chromosome bearing spermatozoa sorted by high speed flow cytometry. Theriogenology 50 981-988.

Aitken RJ \& Baker MA 2004 Oxidative stress and male reproductive biology. Reproduction, Fertility \& Development 16 581-588.

Bathgate R, Eriksson B, Maxwell WMC \& Evans G 2005 Low dose deep intrauterine insemination of sows with fresh and frozen-thawed spermatozoa. Theriogenology 63 553-554.

Bathgate R, Grossfeld R, Susetio D, Ruckholdt M, Heasman K, Rath D, Evans G, \& Maxwell WMC 2008 Early pregnancy loss in sows after low dose, deep uterine artificial insemination with sex-sorted, frozen-thawed sperm. Animal Reproduction Science 104 440-444.

Bathgate R, Maxwell WMC \& Evans G 2006 Studies on the effect of supplementing boar semen cryopreservation media with different avian egg yolk types on in vitro post-thaw sperm quality. Reproduction in Domestic Animals 41 68-73.

Bathgate R, Maxwell WMC\& Evans G 2007a Effects of platelet-activating factor and platelet activating factor acetylhydrolase on in vitro post-thaw boar sperm parameters. Theriogenology 67 886-892.

Bathgate R, Morton KM, Eriksson BM, Rath D, Seig B, Maxwell WMC \& Evans G 2007b Non-surgical deep intra-uterine transfer of in vitro produced porcine embryos derived from sex-sorted frozen-thawed boar sperm. Animal Reproduction Science 99 82-92.

Bianchi I, Calderam K, Maschio EF, Madeira EM, da Rosa Ulguim R, Corcini CD, Bongalhardo DC, Correa EK, Lucia T Jr, Deschamps JC et al. 2008 Evaluation of amides and centrifugation temperature in boar semen cryopreservation. Theriogenology $69632-638$.

Bolarin A, Hernández M, Vazquez IM, Martinez EA \& Roca / 2008 Influence of Seasonality on Reproductive Performance of Sows Inseminated with FrozenThawed Semen. Reproduction in Domestic Animals
4366 (Abstract).

Bolarin A, Roca J, Rodriguez-Martinez H, Hernández M, Vazquez IM \& Martinez EA 2005 Dissimilarities in sows' ovarian status at the insemination time could explain differences in fertility between farms when f́rozen-thawed semen is used. Theriogenology 65 669-680.

Bravo MM, Aparacio IM, Garcia-Herreros M, Gil MC, Pena FJ \& Garcia-Marin LJ 2005 Changes in tyrosine phosphorylation associated with true capacitation and capacitation-like state in boar spermatozoa. Molecular Reproduction and Development 71 88-98.

Breininger E, Beorlegui NB, O'Flaherty CM \& Beconi MT 2005 Alpha-tocopherol improves biochemical and dynamic parameters in cryopreserved boar semen. Theriogenology 63 2126-2135.

Buranaamnuay K, Tummaruk P, Singlor J, RodriguezMartinez H \& Techakumphu M 2009 Effects of straw volume and Equex-STM ${ }^{\circ}$ on boar sperm quality after cryopreservation. Reproduction in Domestic Animals 44 69-73.

Bwanga CO, Einarsson S \& Rodriguez-Martinez H 1991b Freezing of boar semen in plastic bags and straws. Reproduction in Domestic Animals 26 117-125.

Bwanga CO, Ekwall H \& Rodriguez-Martinez H 1991a Cryopreservation of boar semen: III- Ultrastructure of boar spermatozoa frozen ultra-rapidly at various stages of conventional freezing/thawing. Acta Veterinaria Scandinavica 32 463-471.

Caballero I, Vazquez IM, García EM, Parrilla I, Roca J, Calvete JJ, Sanz, L\& Martinez EA 2008 Major proteins of boar seminal plasma as a tool for biotechnological preservation of spermatozoa. Theriogenology 70 1352-1355.

Caballero I, Vazquez IM, Gil MA, Calvete J, Roca I, Sanz L., Parrilla I, García EM, Rodriguez-Martinez H \& Martínez EA 2004 Does seminal plasma PSP-I/ PSP-Il spermadhesin modulate the ability of boar spermatozoa to penetrate homologous oocyles in vitro? Journal of Andrology 25 1004-1012.

Calvete IJ, Raida M, Gentzel M, Urbanke C, Sanz L \& Töpfer-Petersen E 1997 Isolation and characterization of heparin-and phosphorylcholine-binding proteins of boar and stallion seminal plasma. Primary structure of porcine pB1. FEBS Letters 407 201-206.

Cerolini S, Maldiian A, Surai P \& Noble R 2000 Viability, susceptibility to peroxidation and fatty acid composition of boar semen during liquid storage. 
Animal Reproduction Science 58 99-111.

Clulow JR, Maxwell WMC, Evans G \& Morris I.HA 2007 A comparison of duck and chicken egg yolk for cryopreservation of stallion sperm. Australian Veteetrinary lournal 85 232-235.

De Pauw I, Van Soom A, Laevens H, Verberckmoes S \& de Kruif A 2002 Sperm binding to epithelial oviduct explants in bulls with different non-return rates investigated with a new in vitro model. Biology of Reproduction 67 1073-1079.

Demianowicz W \& Strzezek J 1996 The effect of lipoprotein fraction of egg yolk on some of the biological properties of boar spermatozoa during storage of the semen in liquid state. Reproduction in Domestic Animals 31 279-280.

Devireddy RV, Fahrig B, Godke RA \& Leibo SP 2004 Subzero water transport characteristics of boar spermatozoa confirm observed optimal cooling rates. Molecular Reproduction and Development 67 446-457.

Dostalova Z, Calvete J, Sanz L \& Töpfer-Petersen E 1994 Quantitation of boar spermadhesins in accessory sex gland fluids and on the surface of epididymal, ejaculated and capacitated spermatozoa. Biochimica et Biophysica Acta 1200 48-54.

Ekhlasi-Hundrieser $M$, Gohr K, Wagner A, Tsolova $M$, Petrunkina A \& Töpfer-Petersen E 2005 Spermadhesin $A Q N 1$ is a candidate receptor molecule involved in the formation of the oviductal sperm reservoir in the pig. Biology of Reproduction 73 536-545.

Ekwall H 2009 Cryo-scanning electron microscopy discloses differences in dehydration of frozen boar semen stored in large containers. Reproduction in Domestic Animals 44 62-68.

Ekwall H, Hernández M, Saravia F \& Rodríguez-Martínez H 2007 Cryo-scanning electron microscopy (CryoSEM) of boar semen frozen in medium-straws and MiniFlatPacks. Theriogenology 67 1463-1472.

El-Haji Ghaoui R, Thomson PC, Leahy T, Evans G \& Maxwell WMC 2007 Autologous whole ram seminal plasma and its vesicle-free fraction improve motility characteristics and membrane status but not in vivo fertility of frozen-thawed ram spermatozoa. Reproduction in Domestic Animals 42 541-549.

Eriksson BM \& Rodriguez-Martinez H 2000a Deep freezing of boar semen in plastic film "Cochettes". Journal of Veterinary Medicine Series A 47 89-97.

Eriksson BM \& Rodriguez-Martinez H 2000b Effect of freezing and thawing rates on the post-thaw viability of boar spermatozoa frozen in large $5 \mathrm{ml}$ packages (FlatPack). Animal Reproduction Science 63 205-220.

Eriksson BM, Petersson H \& Rodriguez-Martinez 2002 Field fertility with exported boar semen frozen in the new FlatPack container. Theriogenology 58 1065-1079.

Fraser L \& Strzezek J 2005 Effects of freezing-thawing on DNA integrity of boar spermatozoa assessed by the neutral comet assay. Reproduction in Domestic Animals $40530-536$.
Fraser L \& Strzezek J 2007a Effect of different procedure of ejaculate collection extenders and packages on DNA integrity of boar spermatozoa following freezingthawing. Animal Reproduction Science 99 317-329.

Fraser L \& Strzezek J 2007b Is there a relationship between chromatin status and ONA fragmentation of boar spermatozoa following freezing-lhawing? Theriogenology 68 248-257.

Fraser L, Dziekonska A, Strzezek R \& Strzezek J 2007a Dialysis of boar semen prior to freezing-thawing. Its effects on post-thaw sperm characteristics. Theriogenology 67 994-1003.

Fraser L, Strzezek R \& Strzezek | 2007b Fertilizing capacity of boar semen frozen in an extender supplemented with ostrich egg yolk lipoprotein fractions - A pilot study. Polish lournal of Veterinary Sciences 10 131-135.

Frenette G, Lessard C \& Sullivan R 2002 Selected proteins of 'prostasome-like particles' from epididymal cauda fluid are transferred to epididymal caput spermatozoa in bull. Biology of Reproduction 67 308-313.

Fuller B] 2004 Cryoprotectants: The essential antifreezes to protect life in the frozen state. Cryoletters 25 375-388.

Gadea J, Garcia-Vazquez F, Matas C, Gardon JC, Canovas S \& Gumbao D 2005 Cooling and freezing of boar spermatozoa: Supplementation of the freezing media with reduced glutathione preserves sperm function. Journal of Andrology 26 396-404.

Gadella BM \& Harrison RAP 2002 Capacitation induces cyclic adenosine $3^{\circ}, 5^{\circ}$-monophosphatedependent, but apoptosis unrelated, exposure of aminophospholipids at the apical head plasma membrane of boar sperm cells. Biology of Reproduction 67 340-350.

García EM, Vázquez IM, Parrilla I, Calvete IJ, Sanz L, Caballero I, Roca J, Vazquez JL \& Martínez EA 2007 Improving the fertilizing ability of sex sorted boar spermatozoa. Theriogenology 68 771-778.

Garcia JC, Abad M \& Kirkwood RN 2007 Effect of sperm numbers and time of insemination relative to ovulation on sow fertility. Animal Reproduction Science $\mathbf{1 0 0}$ $397-401$.

Gilmore JA, Du J, Tao J, Peter AT \& Critser JK 1996 Osmotic properties of boar spermatozoa and their relevance to cryopreservation. Journal of Reproduction and Fertility 107 87-95.

Green CE \& Watson PF 2001 Comparison of the capacitation-like state of cooled boar spermatozoa with true capacitation. Reproduction 122 889-898.

Grossfeld R, Klinc P, Sieg B \& Rath D 2005 Production of piglets with sexed semen employing a nonsurgical insemination technique. Theriogenology 63 2269-2277.

Grossfeld R, Sieg B, Struckmann C, Frenzel A, Maxwell WM \& Rath D 2008 New aspects of boar semen freezing strategies. Theriogenology $701225-1233$.

Guthrie HD \& Welch GR 2005a Effects of hypothermic liquid storage and cryopreservation on basal and induced plasma membrane phospholipid disorder 
and acrosome exocytosis in boar spermatozoa. Reproduction, Fertility \& Development 17 467-477.

Guthrie HD \& Welch GR 2005b Impact of storage prior to cryopreservation on plasma membrane function and fertility of boar sperm. Theriogenology 63 396-410.

Han B \& Bischof JC 2004 Thermodynamic nonequilibrium phase change behaviour and thermal properties of biological solutions for cryobiology applications. Journal of Biomechanical Engineering 126 196-203.

Harrison RA, Ashworth PJC \& Miller NGA 1996 Bicarbonate/ $/ \mathrm{CO}_{2}$, an effector of capacitation, induces a rapid and reversible change in the lipid architecture of boar sperm plasma membranes. Molecular Reproduction and Development 45 378-391.

Hernández M, Roca J, Ballester J, Vázquez JM, Martinez EA, Johannisson A, Saravia F \& Rodriguez-Martinez H 2006 Differences in SCSA outcome among boars with different sperm freezability. International journal of Andrology 29 583-591.

Hernández M, Roca J, Calvete JJ, Sanz L, Muiño-Blanco T \& Cebrian-Perez JA 2007a Cryosurvival and in vitro fertilizing capacity postthaw is impoved when boar spermatozoa are frozen in the presence of seminal plasma from good freezer boars. Journal of Andrology 28 689-697.

Hernández M, Roca J, Gil MA, Vazquez JM \& Martinez EA 2007b Adjustments on the cryopreservation conditions reduce the incidence of boar ejaculates with poor sperm freezability. Theriogenology 67 1436-1445.

Hernández M, Vazquez JM, Martinez EA \& Roca | 2007c Oxidative stress during the cryopreservation of boar spermatozoa. Reproduction, Fertility \& Development 19177.

Holt WV \& Harrison RAP 2002 Bicarbonate stimulation of boar sperm motility via a protein kinase A-dependent pathway: between-cell and between-ejaculate differences are not due to deficiencies in protein kinase A activation. Journal of Andrology 23 557-565.

Holt WV, Medrano A, Thurston LM \& Watson PF 2005 The significance of cooling rates and animal variability for boar sperm cryopreservation: insights from the cryomicroscope. Theriogenology 63 370-382.

Holt WV, O'Brien I \& Abaigar T 2007 Applications and interpretation of computer-assisted sperm analyses and sperm sorting methods in assisted breeding and comparative research. Reproduction, Fertility \& Development 19 709-718.

Hu JH, Li QW, Jiang ZL \& Li WY 2008 Effects of different extenders on DNA integrity of boar spermatozoa following freezing-thawing. Cryobiology 57 257-262.

Jiang ZL, Li QW, Li WY, Hu JH, Zhao HW \& Zhang SS 2007 Effect of low density lipoprotein on DNA integrity of freezing-thawing boar sperm by neutral comet assay. Animal Reproduction Science 99 401-407.

Johnson LA 1991 Sex pre-selection in swine: altered sex ratios in offspring following surgical insemination of flow sorted $\mathrm{X}$ - and $\mathrm{Y}$-bearing sperm. Reprod Dom Anim 26 309-314.
Johnson LA, Weitze KF, Fiser P \& Maxwell WM 2000 Storage of boar semen. Animal Reproduction Science 18 43-172.

Karosas J \& Rodriguez-Martinez H 1993 Use of two detergents for freezing of boar semen in plastic bags. Biomedical Research 4 125-136.

Khalil AAY, Petrunkina AM, Sahin E, Waberski D \& Töpfer-Petersen E 2006 Enhanced binding of sperm with superior volume regulation to oviductal epithelium. Journal of Andrology 27 754-765.

Kordan W \& Strzezek J 2002 Effect of platelet-activating factor on motility parameters and plasmalemma integrity of boar spermatozoa. Animal Science Papers and Reports 20 37-45.

Kravets FG, Lee J, Singh B, Trocchia A, Pentyala SN \& Khan SA 2000 Prostasomes: current concepts. Prostate 43 169-174.

Larsson K \& Einarsson S 1976 influence of boars on the relationship between fertility and post thawing sperm quality of deep frozen boar spermatozoa. Acta Veterinaria Scandinavica 17 74-82.

Lin C, Tholen E, Jennen D, Ponsuksili S, Schellander K \& Wimmers K 2006 Evidence for effects of testis and epididymis expressed genes on sperm quality and fertility traits. Reproduction in Domestic Animals 41 538-543.

Loomis PR \& Graham JK 2008 Commercial semen freezing: individual male variation in cryosurvival and the response of stallion sperm to customized freezing protocols. Animal Reproduction Science 105 119-128.

Lusignan M-F, Bergeron A, Crete $\mathbf{M}-\mathbf{H}$, Lazure $\mathbf{C}$ \& Manjunath P 2007 Induction of epididymal boar sperm capacitation by $\mathrm{PB} 1$ and $\mathrm{BSP}-\mathrm{A} 1 / \mathrm{-A} 2$ proteins, members of the BSP protein family. Biology of Reproduction 76 424-432.

Manjunath P, Nauc V, Bergeron A \& Menard M 2002 Major proteins of bovine seminal plasma bind to the low-density lipoprotein fraction of hen's egg yolk. Biology of Reproduction 67 1250-1258.

Martin G, Sabido O, Durand P \& Levy R 2004 Cryopreservation induces an apoptosis like mechanism in bull sperm. Biology of Reproduction 71 28-37.

Martin G, Sabido O, Durand P \& Levy R 2005 Phosphatidylserine externalization in human sperm induced by calcium ionophore A23187: relationship with apoptosis, membrane scrambling and the acrosome reaction. Human Reproduction 20 3459-3488.

Maxwell WMC, de Graaf SP, El-Hajj Ghaoui R \& Evans G 2007 Seminal plasma effects on sperm handling and female fertility. In Reproduction in Domestic Ruminants VI, pp 13-38. Eds JL Juengel, JF Murray \& MF Smith. Nottingham: Nottingham University Press.

Medrano A, Anderson J, Millar JD, Holt WV \& Watson PF 2002b A custom-built controlled-rate freezer for small sample cryopreservation studies. Cryoletters 23 397-404.

Medrano A, Watson PF \& Holt WV 2002a Importance 
of cooling rate and animal variability for boar sperm cryopreservation: insights from the cryomicroscope. Reproduction $123315-322$.

Moore HDM \& Hibbitt KG 1977 Fertility of boar spermatozoa after freezing in the absence of seminal vesicular proteins. Journal of Reproduction and Fertility 50 349-352.

Morris GJ 2006 Rapidly cooled human sperm: no evidence of intracellular ice formation. Human Reproduction 21 2075-2083.

Morris GJ, Faszer K, Green IE, Draper D, Grout BW \& Fonseca F 2007 Rapidly cooled horse spermatozoa: loss of viability is due to osmotic imbalance during thawing, not intracellular ice formation. Theriogenology 68 804-812.

Morris GJ, Goodrich M, Acton E \& Fonseca F 2006 The high viscosity encountered during freezing in glycerol solutions: effects on cryopreservation. Cryobiology 52 323-334.

Moussa $M$, Martinet $V$, Trimeche A, Tainturie D \& Anton M 2002 Low density lipoproteins extracted from hen egg yolk by an easy method: cryoprotective effect on frozen-thawed bull semen. Theriogenology 57 1695-1706.

Muiño-Blanco T, Perez-Pe R \& Cebrian-Perez IA 2008 Seminal plasma proteins and sperm resistance to stress. Reproduction in Domestic Animals 43 (Suppl 4) 18-31.

Mwanza A \& Rodriguez-Martinez H 1993 Post-thaw motility, acrosome morphology and fertility of deep frozen boar semen packaged in plastic PVC-bags. Biomedical Research 4 21-29.

Ortman K \& Rodriguez-Martinez H 1994 Membrane damage during dilution, cooling and freezing-thawing of boar spermatozoa packaged in plastic bags. Journal of Veterinary Medicine Series A 41 37-47.

Peña Fl, Johannisson A, Wallgren M \& RodriguezMartinez H 2003 Antioxidant supplementation in vitro improves boar sperm motility and mitochondrial membrane potential after cryopreservation of different fractions of the ejaculate. Animal Reproduction Science 78 85-98.

Peña FJ, Johannisson A, Wallgren M \& Rodriguez-Martinez H 2004 Effect of hyaluronan supplementation on boar sperm motility and membrane lipid architecture status after cryopreservation. Theriogenology 61 63-70.

Peña Fl, Rodriquez-Martinez H, Tapia JA, Ortega Ferrusola C, Conzales Fernandez L \& Macias Garcia B 2009 Mitochondria in mammalian sperm physiology and pathology: A review. Reproduction in Domestic Animals 44 345-349.

Pérez-Llano B, Lorenzo JL, Yenes P, Trejo A, GarcíaCasado P 2001 A short hypoosmotic swelling test for the prediction of boar sperm fertility. Theriogenology 56 387-98.

Petrunkina AM, Petzoldt R, Stahlberg R, Pfeilsticker I, Beyerbach M, Bader \& Töpfer-Petersen E 2001 Sperm-cell volumetric measurements as parameters in bull semen function evaluation: correlation with nonreturn rate. Andrologia 33 360-367.
Petrunkina AM, Waberski D, Günzel-Apel AR \& TöpferPetersen E 2007 Determinants of sperm quality and fertility in domestic species. Reproduction 134 3-17.

Pettitt MJ, Buhr MM 1998 Extender components and surfactants affect boar sperm function and membrane behavior during cryopreservation. Journal of Andrology 19 736-746.

Plucienniczak G, Jagiello A, Plucienniczak A, Holody D \& Strzezek J 1999 Cloning of complementary DNA encoding the pB1 component of the 54-kilodalton glycoprotein of boar seminal plasma. Molecular Reproduction and Development 52 303-309.

Probst S \& Rath D 2003 Production of piglets using intracytoplasmic sperm injection (ICSI) with flow cytometrically sorted boar semen and artificially activated oocytes. Theriogenology 59 961-973.

Pursel VG \& Johnson LA 1975 Freezing of boar spermatozoa: fertilizing capacity with concentrated semen and a new thawing procedure. lournal of Animal Science 40 99-102.

Rath D \& Niemann H 1997 In vitro fertilization of porcine oocytes with fresh and frozen-thawed ejaculated or frozen-thawed epididymal semen obtained from identical boars. Theriogenology 47 785-793.

Rath D, Johnson LA, Dobrinsky JR, Welch GR \& Niemann $H 1997$ Production of piglets preselected for sex following in vitro fertilization with $X$ and $Y$ chromosome-bearing spermatozoa sorted by flow cytometry. Theriogenology 47 795-800.

Rath D, Long CR, Dobrinsky JR, Welch GR, Schreier LL. \& Johnson LA 1999 In Vitro Production of Sexed Embryos for Gender Preselection: High-Speed Sorting of X-Chromosome-Bearing Sperm to Produce Pigs After Embryo Transfer. Journal of Animal Science 77 3346-3352.

Rath D, Ruiz S \& Sieg B 2003 Birth of female piglets following intrauterine insemination of a sow using flow cytometrically sexed boar semen. The Veterinary Record 152 400-401.

Roca J, Carvajal G, Lucas X, Vazquez JM \& Martinez EA 2003 Fertility of weaned sows after deep intrauterine insemination with a reduced number of frozen-thawed spermatozoa Theriogenology 60 77-87.

Roca J, Gil MA, Hernández M, Parrilla I, Vázquez JM, Martínez EA 2004 Survival and fertility of boar spermatozoa after freeze-thawing in extender supplemented with butylated hydroxytoluene. Journal of Andrology 25 389-396.

Roca I, Hernández M, Carvajal G, Vazquez IM \& Martinez. EA 2006a Factors influencing boar sperm cryosurvival Journal of Animal Science 84 2692-2699.

Roca J, Rodríguez MJ, Gil MA, Carvajal G, García EM, Cuello C, Vázquez JM, Martinez EA 2005 Survival and in vitro fertility of boar spermatozoa frozen in the presence of superoxide dismutase or catalase or both. lournal of Andrology 26 15-24.

Roca J, Rodriguez-Martinez $\mathrm{H}$, Vazquez JM, Bolarin A, Hernández M, Saravia F, Waltgren M \& Martinez EA 2006b Strategies to improve the fertility of frozenthawed boar semen for artificial insemination. In 
Control of Pig Reproduction VII, pp. 261-275. Eds C) Ashworth \& RR Kraeling. Nottingham: Nottingham University Press.

Roca J, Vazquez JM, Gil MA, Cuello C, Parrilla I \& Martinez EA 2006c Challenges in pig artificial insemination. Reproduction in Domestic Animal 41 43-53.

Rodriguez Martinez H, Iborra A, Martinez P \& Calvete J) 1998 Immunoelectronmicroscope imaging of spermadhesin AWN epitopes on boar spermatozoa bound in vivo to the zona pellucida. Reproduction Fertility \& Development $10491-497$.

Rodriguez-Martinez H 2007 State of the art in farm animal sperm evaluation. Reproduction, Fertility \& Development 19 91-101.

Rodriguez-Martinez H, Saravia F, Wallgren M, Roca J \& Peña FJ 2008 Influence of seminal plasma on the kinematics of boar spermatozoa during freezing. Theriogenology 70 1242-1250.

Rodriguez-Martinez $H$, Saravia F, Wallgren $M$, Tienthai P, Johannisson A, Vázquez IM, Martínez E, Roca J, Sanz L \& Calvete IJ 2005 Boar spermatozoa in the oviduct. Theriogenology 63 514-535.

Saravia F, Hernández $M$, Wallgren $M$, Johannisson A \& Rodriguez-Martinez H 2007 Controlled cooling during semen cryopreservation does not induce capacitation of spermatozoa from two portions of boar ejaculate. International journal of Andrology 30 485-499.

Saravia F, Wallgren M \& Rodríguez-Martínez H 2009a Freezing of boar semen can be simplified by handling a specific portion of the ejaculate with a shorter procedure and MiniFlatPack packaging. Anim Reprod Sci (In press, doi: 10.1016/j.anireprosci.2009.0.4.014)

Saravia F, Waltgren $M$, Johannison A, Calvete J, Sanz L, Pena Fl, Roca I \& Rodriguez-Martinez H 2009 b Exposure to the seminal plasma of different portions of the boar ejaculate modulates the survival of spermatozoa cryopreserved in MiniFlatPacks. Theriogenology 71 662-675.

Saravia F, Wallgren M, Nagy S, Johannisson A \& RodriguezMartinez H 2005 Deep freezing of concentrated boar semen for intra-uterine insemination: effects on sperm viability. Theriogenology 63 1320-1333.

Satake N, Elliot RMA, Watson PF \& Holt WV 2006 Sperm selection and competition in pigs may be mediated by the differential motility activation and suppression of sperm subpopulations within the oviduct. Journal of Experimental Biology 209 1560-1572.

Satorre MM, Breininger E, Beconi MT \& Beorlegui NB 2007 a-Tocopherol modifies tyrosine phosphorylation and capacitation-like state of cryopreserved porcine sperm. Theriogenology 68 958-965.

Silva PFN \& Gadella BM 2006 Detection of damage in mammalian sperm cell. Theriogenology 65 958-978.

Soede NM \& Kemp B 1997 Expression of oestrus and timing of ovulation in pigs. Journal of Reproduction and Fertility 52 (Suppl.) 91-103.

Strzezek J, Fraser L, Lecewicz M \& Dziekońska A 2004 Aplicaciones bioquímicas y prácticas de un diluyente para la conservación liquida de semen de verraco a $5^{\circ}$ y $16^{\circ} \mathrm{C}$. AVANCES en Tecnologia Porcina 1 51-66.

Strzezek J, Glogowski J, Hopfer E \& Wojtkiewicz K 1985 The "Kortowska" method of freezing boar semen. Med Vet 41 349-353.

Strzezek J, Lecewicz M, Dziekonska A \& Fraser L 2005a A simple method of extraction of lipoprotein fractions from avian egg yolk - protective effect on cooled boar semen. Theriogenology 63 496-497.

Strzezek J, Wysocki P, Kordan W, Kuklinska $M$, Mogielnicka M, Soliwoda D \& Fraser L 2005b Proteomics of boar seminal plasma - current studies and possibility of their application in biotechnology of animal reproduction. Reproductive Biology 5 279-290.

Thurston LM, Holt WV \& Watson PF 2003 Post-thaw functional staus of boar spermatozoa cryopreserved using three controlled rate freezers: a comparison. Theriogenology 60 101-113.

Thurston LM, Siggins K, Mileham A), Watson PF \& Holt WV 2002 Identification of amplified restriction fragment length polymorphism makers linked to genes controlling boar sperm viability following cryopreservation. Biology of Reproduction 66 545-554.

Thurston LM, Watson PF, Mileham Af \& Holt WV 2001 Morphologically distinct sperm subpopulations defined by Fourier shape descriptors in fresh ejaculates correlate with variation in boar semen quality following cryopreservation. Journal of Andrology 22 382-394.

Urner F \& Sakkas D 2003 Protein phosphorylation in mammalian spermatozoa. Reproduction 125 17-26.

Vazquez JM, Roca J, Gil MA, Cuello C, Parrilla I, Vazquez JL \& Martinez EA 2008 New developments in lowdose insemination technology. Theriogenology $\mathbf{7 0}$ 1216-1224.

Veselský L, Jonáková V, Sanz L, Töpfer-Petersen E \& Cechová D 1992 Binding of a 15 kDa glycoprotein from spermatozoa of boars to surface of zona pellucida and cumulus oophorus cells. Journal of Reproduction and Fertility 96 593-602.

Vishwanath R, Shannon P \& Curson B 1992 Cationic extracts of egg yolk and their effects on motility, survival and fertilising ability of bull sperm. Animal Reproduction Science 29 185-194.

Waterhouse KE, Hofmo PO, Tverdal A \& Miller RR Jr 2006 Within and between breed differences in freezing tolerance and plasma membrane fatty acid composition of boar sperm. Reproduction 131 887-894.

Watson PF \& Behan JR 2002 Intrauterine insemination of sows with reduced sperm numbers: results of a commercially based field trial. Theriogenology 57 1683-1693.

Watson PF 1995 Recent developments and concepts in the cryopreservation of spermatozoa and the assessment of their post-thawing function. Reproduction, Fertility and Development 7 871-891.

Watson PF 2000 The causes of reduced fertility with cryopreserved semen. Animal Reproduction Science 60-61 481-492. 
Weitze KF, Rath D \& Baron G 1987 Neue Aspekte der Tiefgefrierkonservierung von Ebersperma in Plastikrohren. Deutsche Tierärztliche Wochenschrift 82 261-267.

Westendorf P, Richter L \& Treu H 1975 Deep freezing of boar sperma. Laboratory and insemination results using the Hülsenberger paillete method. Deutsche Tieraerztliche Wochenschrift 5 261-267

Woelders H \& Chaveiro A 2004 Theoretical prediction of "optimal" freezing programmes. Cryobiology 49 258-271.

Woelders H, Matthijs A \& Den Beston M 1996 Boar variation in "freezability" of the semen. Reproduction in Domestic Animals 31 153-159.

Woelders H, Matthijs A, Zuidberg CA \& Chaveiro AE 2005 Cryopreservation of boar semen: equilibrium freezing in the cryomicroscope and in straws. Theriogenology 163 383-395.

Wongtawan $T$, Saravia F, Wallgren $M$, Caballero I \& Rodríguez-Martínez H 2006 Fertility after deep intra-uterine artificial insemination of concentrated low-volume boar semen doses. Theriogenology 65 773-787.
Wysocki P \& Strzezek J 2003 Purification and characterization of protein tyrosine acid phosphatase from boar seminal vesicle glands. Theriogenology 59 $1011-1025$.

Wysocki P \& Strzezek J 2006 Isolation and biochemical characteristics of molecular form of epididymal acid phosphatase of boar seminal plasma. Theriogenology 66 2152-2159.

Wysocki P, Koncicka K \& Strzezek J 2009 Is the phosphorylation status of tyrosine proteins a marker for cryo-capacitation of boar spermatozoa? Bulletin of the Veterinary Institute in Pulawy (in Press).

Yi YJ, Cheon YM \& Park CS 2002a Effect of $\mathrm{N}$-acetylD-glucosamine, and glycerol concentration and equilibrium time on acrosome morphology and motility of frozen-thawed boar sperm. Animal Reproduction Science 69 91-97.

Yi Y), Im CS \& Park CS 2002b Lactose-egg yolk diluent supplemented with $\mathrm{N}$-acetyl-D-glucosamine affect acrosome morphology and motility of frozen-thawed boar sperm. Animal Reproduction Science $\mathbf{7 4}$ 187-194. 